\title{
Partially Funded Social Security and Inter-Generational Distribution
}

\author{
Hyeon Park \\ Department of Economics and Finance, Manhattan College, New York, USA \\ Email: hyeon.park@manhattan.edu
}

Received 16 October 2014; revised 23 November 2014; accepted 5 December 2014

Copyright (C) 2014 by author and Scientific Research Publishing Inc.

This work is licensed under the Creative Commons Attribution International License (CC BY). http://creativecommons.org/licenses/by/4.0/

(c) (i) Open Access

\section{Abstract}

This paper introduces a parametric model of partially funded social security system and analyzes inter-generational distribution of consumption and welfare in an OLG general equilibrium. This paper specifically aims to examine the effects of transition toward more funded system on saving and capital accumulation. It is shown that an increase in intensity of fundedness increases capital accumulation unless the income effect from interest rate change outweighs other effects and negatively affects the total saving severely. By deriving closed form solutions for the variables, this paper finds that an increase in the intensity of fundedness increases saving but decreases consumption, when population growth rate is greater than the net return to capital. This paper also finds that for a partially funded system, an increase in tax rate increases public saving but reduces private saving unambiguously, while the effects on consumption and capital accumulation are not conclusive.

\section{Keywords}

Partially Funded Social Security, Inter-Generational Distribution, Welfare

\section{Introduction}

This paper introduces a parametric model of a comprehensive social security system, by which different social security plans are represented via certain degrees of fundedness. As pointed out by many researchers including Feldstein, Kunze, and Kaganovich and Zilcha [1]-[3], the transition from an unfunded pension system to a fully funded or more funded one may be necessary due to the demographic change toward aging society ${ }^{1}$ in many developed countries. Based on this notion, this paper develops a model of a unified pension system that can di-

\footnotetext{
${ }^{1}$ Regarding social security with other consideration such as aging population, see Pecchenino and Utendorf, and others [4]-[12].
} 
rectly show the transition effect of the system on many variables related with welfare and growth ${ }^{2}$. This paper particularly assumes a generic social security system financed by a payroll tax but parameterized by the intensity of fundedness. Thus given any payroll tax rate, the funded portion is to be invested for the pension income of current young for their retirement years, while the remaining portion to be transferred to current old as their pension benefits. Zero fundedness specifies PAYG system, in which all taxed amount should be used to finance pensions for the current old. If it is the case of full intensity, then the scheme specifies fully-funded social security system. Between these two extremes, there are many partially funded systems. By this model, it is possible to evaluate many types of national pension plans in which different combinations of funded and non-funded are allowed.

With the unified social security system, this paper analyzes inter-generational distribution regarding consumption and welfare in general equilibrium. This paper specifically compares the saving, consumption, and capital accumulation under the three different social security systems, PAYG, Fully Funded, and Partially Funded and examines the effects of alternative system on these variables. One contribution of this paper is to derive closed form solutions for these variables so that direct comparison among different systems is made possible. The solution is based on the maximization problem of two-period intertemporal choice model in an environment of OLG production economy populated by young generations who work, consume and save and the old who consume out of their personal savings and/or public pensions. It is well known that a social security system gives the old generation opportunities to smooth out consumption stream over time. However there is crowding-out effect between private saving and public saving and the effect largely depends on the size of fundedness. When the interest rate increases, given fundedness intensity, it increases public saving/transfer. But this in turn tends to decrease the incentive for private saving, while the private saving itself is subject to income and substitution effects in an inter-temporal choice when there is a change in interest rate. The result shows that increase in intensity of fundedness increases capital accumulation under the condition that the total saving would not decrease a lot from income effect which outweighs substitution effect and others with higher interest rate. Likewise the increase in intensity increases private saving but decreases consumption, when population growth rate is greater than the net return to capital. This paper also finds that, for a partially funded system, an increase in tax rate increases public saving but reduces private saving unambiguously, while the effects on consumption and capital accumulation are not conclusive.

\section{The Model}

\subsection{Environment}

Time is discrete. Consider an overlapping generation model for $t=0,1,2, \cdots$, where each individual lives for two periods $s=1,2$, i.e., the young who works, consumes and saves and the old who consumes. At each time $L_{t}$ individuals are born and the population is grown at a rate of $n$. Thus it is satisfied that $L_{t}=(1+n) L_{t-1}$ and $L_{t}=L_{0}(1+n)^{t}$. Because the individuals live for two periods, at time $t$ there are $L_{t}$ individuals who are in their first stage of life, i.e., young and $L_{t-1}=L_{t} /(1+n)$ individuals who are in their second stage. Each agent is endowed with $e_{t}$ efficient unit of labor when young and earns income of $w_{t} e_{t}$, where $w_{t}$ is the market determined wage rate. When the agent is old, he consumes private saving from the first period, together with social security benefit. There is no labor income in the second period. The financial income at the second period from private saving is $\left(1+r_{t+1}\right) S_{1 t+1}$, where $S_{1 t+1}$ is the saving of young made at time $t$ for the next period and $r_{t+1}$ is the market determined interest rate. Let $c_{1 t}$ and $c_{2 t+1}$ be the consumption of an agent who is young at $t$ and old at $t+1$. There exist initial old agents who own capital stock and this capital stock $K_{0}$ is distributed equally by all old individuals. Lastly, there is no bequest by the old and the economy is closed.

\section{Social Security System}

There is a government who implements a generic social security system financed by a payroll tax of $\tau_{t}$, parameterized by the intensity $\phi \in[0,1]$ of fundedness such that $\phi \tau_{t}$ is the portion to be invested for the future social security income of current young agents for their retirement years. This means that only a fraction of taxed amount is utilized for the benefit of retirement account holders, and the remaining portion $(1-\phi) \tau_{t}$ is used to pay for benefits of the current old. Thus, under this system old individuals at time $t$ receive social se-

\footnotetext{
${ }^{2}$ Regarding the relationship between the size of an unfunded public pension system and economic growth, see Lambrecht, Michel, and Vidal [13].
} 
curity income of $\phi\left(1+r_{t}\right) \tau_{t-1} w_{t-1} e_{t-1}+(1-\phi)(1+n) \tau_{t} w_{t} e_{t}$, where $\tau_{t}$ is the social security tax collected from current young agents at time $t$ and $w_{t} e_{t}$ is their labor income ${ }^{3}$. Regarding pension plan, if $\phi=0$, then this model specifies PAYG system, while if $\phi=1$, the model implies Fully-Funded system. Between these two extremes, there stand many partially funded ones.

\subsection{Household's Optimization}

Suppose that young households at time $t$ have time separable utility and choose consumption and saving level to maximize their lifetime welfare. Young agents born in period $t$ solve the following maximization problem in which the periodic utility is specified by CRRA ${ }^{4}$.

$$
\operatorname{Max}_{t}\left(c_{1 t}, c_{2 t+1}\right)=\frac{c_{1 t}^{1-\gamma}}{1-\gamma}+\beta \frac{c_{2 t+1}^{1-\gamma}}{1-\gamma}
$$

subject to

$$
\begin{aligned}
& c_{1 t}+S_{1 t+1}=\left(1-\tau_{t}\right) w_{t} e_{t} \\
& c_{2 t+1}=\left(1+r_{t+1}\right) S_{1 t+1}+T_{t+1}
\end{aligned}
$$

with $c_{1 t} \geq 0, \quad c_{2 t+1} \geq 0$ and the social security income

$$
T_{t+1}=\phi\left(1+r_{t+1}\right) \tau_{t} w_{t} e_{t}+(1-\phi)(1+n) \tau_{t+1} w_{t+1} e_{t+1}
$$

The second budget constraint shows that old households live on both private saving $S_{1 t+1}$ and public saving (or public transfer) ${ }^{5} T_{t+1}$. Solving the household problem yields the following saving $S_{1 t+1}$ by the young households at first period for the next.

$$
S_{1 t+1}=\frac{\left[\beta\left(1+r_{t+1}\right)\right]^{\frac{1}{\gamma}}\left(1-\tau_{t}\right) w_{t} e_{t}-T_{t+1}}{\left(1+r_{t+1}\right)+\left[\beta\left(1+r_{t+1}\right)\right]^{\frac{1}{\gamma}}}
$$

with $T_{t+1}$ as defined in Equation (4). Notice that the saving is a function of both interest rate and wage rate, as well as other parameters. Plugging $S_{1 t+1}$ into the household budget constraints yields the following life time consumption profile.

$$
\begin{gathered}
c_{1 t}=\frac{\left(1+r_{t+1}\right)\left(1-\tau_{t}+\phi \tau_{t}\right) w_{t} e_{t}+(1-\phi)(1+n) \tau_{t+1} w_{t+1} e_{t+1}}{\left(1+r_{t+1}\right)+\left[\beta\left(1+r_{t+1}\right)\right]^{\frac{1}{\gamma}}} \\
c_{2 t+1}=\left[\beta\left(1+r_{t+1}\right)\right]^{\frac{1}{\gamma}}\left(\frac{\left(1+r_{t+1}\right)\left(1-\tau_{t}+\phi \tau_{t}\right) w_{t} e_{t}+(1-\phi)(1+n) \tau_{t+1} w_{t+1} e_{t+1}}{\left(1+r_{t+1}\right)+\left[\beta\left(1+r_{t+1}\right)\right]^{\frac{1}{\gamma}}}\right)
\end{gathered}
$$

This is the solution to the household maximization problem. Before we get equilibrium with production sector, we want to look for the immediate effect of $\phi$ on the saving function assuming market interest rates and wage rates are given ${ }^{6}$. Later we look for the effect in a general equilibrium where all variables are adjusted and furthermore in steady states so that the effect tells what would happen to the saving rate and other variables in the long run if we move away from non-funded pension program to funded one. From Equation (5), the partial derivative w.r.t. $\phi$ is

$$
\frac{\partial S_{1 t+1}}{\partial \phi}=\frac{(1+n) \tau_{t+1} w_{t+1} e_{t+1}-\left(1+r_{t+1}\right) \tau_{t} w_{t} e_{t}}{\left(1+r_{t+1}\right)+\left[\beta\left(1+r_{t+1}\right)\right]^{\frac{1}{\gamma}}}
$$

\footnotetext{
${ }^{3}$ The government is assumed to be in balanced budget each time.

${ }^{4}$ By this, it is satisfied that $u^{\prime}>0, u^{\prime \prime}<0$ and $\lim _{c \rightarrow 0} u^{\prime}(c)=\infty$.

${ }^{5}$ We may want to use the term public saving for $\left(1+r_{t+1}\right) \tau_{t} w_{t} e_{t}$ and public transfer for $(1+n) \tau_{t+1} w_{t+1} e_{t+1}$.

${ }^{6}$ This implies we are getting the transition effect from a less funded system to more funded one in partial equilibrium.
} 
That is, $\frac{\partial S_{1 t+1}}{\partial \phi} \lessgtr 0$, which implies if $(1+n) \tau_{t+1} w_{t+1} e_{t+1}>\left(1+r_{t+1}\right) \tau_{t} w_{t} e_{t}$ then as fundedness increases private saving by the young households increases. If all the rates are fixed over short period of time, this simply tells that when $1+n>1+r$, the saving increases. In other words, if population growth rate is higher than the interest rate, personal saving increases as we move toward more funded system. This is because their lifecycle income is reduced through lower transfer from young generation due to higher fundedness intensity. In fact, from the social security income equation $T_{t+1}=\phi\left(1+r_{t+1}\right) \tau_{t} w_{t} e_{t}+(1-\phi)(1+n) \tau_{t+1} w_{t+1} e_{t+1}$, as $\phi$ increases the weight of second part of the RHS decreases and this would affect negatively on overall social security income because this part has greater portion in the equation when $1+n>1+r$. Intuitively, with more funded system, young households need to save more because they cannot expect a lot through the transfer from future young generation when they are old. Also the total savings from both private and public ones will be increasing because, for the total saving defined by $Z_{1 t+1}=S_{1 t+1}+\phi\left(1+r_{t+1}\right) \tau_{t} w_{t} e_{t}$, the partial derivative is

$$
\frac{\partial Z_{1 t+1}}{\partial \phi}=\theta(1+n) \tau_{t+1} w_{t+1} e_{t+1}+(1-\theta)\left(1+r_{t+1}\right) \tau_{t} w_{t} e_{t}>0
$$

with $\theta=\frac{1}{\left(1+r_{t+1}\right)+\left[\beta\left(1+r_{t+1}\right)\right]^{\frac{1}{\gamma}}}<1$. This implies that regardless of system, higher fundedness intensity increases total saving, outweighing the possible decrease in private saving. Likewise as shown in Equation (10), the effect on consumption has the opposite direction and thus if $(1+n) \tau_{t+1} w_{t+1} e_{t+1}>\left(1+r_{t+1}\right) \tau_{t} w_{t} e_{t}$ then the consumption decreases as fundedness intensity increases:

$$
\frac{\partial c_{1 t}}{\partial \phi}=\frac{\left(1+r_{t+1}\right) \tau_{t} w_{t} e_{t}-(1+n) \tau_{t+1} w_{t+1} e_{t+1}}{\left(1+r_{t+1}\right)+\left[\beta\left(1+r_{t+1}\right)\right]^{\frac{1}{\gamma}}}
$$

which is greater or lower than zero depending on $\left(1+r_{t+1}\right) \tau_{t} w_{t} e_{t} \lessgtr(1+n) \tau_{t+1} w_{t+1} e_{t+1}$. Of course, when labor income is about the same over time, then the relative size of population growth rate to interest rate determines the direction of consumption change. This is mainly because the consumption is a function of lifecycle income and as explained above the income reduces as $\phi$ gets higher when $1+n>1+r$. Moreover, because $c_{2 t+1}$ is monotonic to $c_{1 t}$, the effect on consumption at second period remains the same. To explore the effect of payroll tax $\tau_{t}$ increase, we assume that the change in tax rate is permanent: $\tau_{t}=\tau_{t+1}=\tau$. Then for a fixed level of $\phi$,

$$
\frac{\partial S_{1 t+1}}{\partial \tau}=-\frac{\left(\left[\beta\left(1+r_{t+1}\right)\right]^{1 / \gamma}+\phi\left(1+r_{t+1}\right)\right) w_{t} e_{t}+(1-\phi)(1+n) w_{t+1} e_{t+1}}{\left(1+r_{t+1}\right)+\left[\beta\left(1+r_{t+1}\right)\right]^{\frac{1}{\gamma}}}<0
$$

This implies that given fundedness intensity, as public saving and transfer increase, the young household's incentive for personal saving decreases. Similarly

$$
\frac{\partial c_{1 t}}{\partial \tau}=(1-\phi) \frac{(1+n) w_{t+1} e_{t+1}-\left(1+r_{t+1}\right) w_{t} e_{t}}{\left(1+r_{t+1}\right)+\left[\beta\left(1+r_{t+1}\right)\right]^{\frac{1}{\gamma}}}
$$

Thus $\frac{\partial c_{1 t}}{\partial \tau} \lessgtr 0$, which explains that given a partially fundedness intensity level $0 \leq \phi<1$, a higher tax rate gives higher consumption among young agents when $(1+n) w_{t+1} e_{t+1}>\left(1+r_{t+1}\right) w_{t} e_{t}$. This is because when the condition is satisfied, the overall lifecycle wealth level is increased ${ }^{7}$. Notice that when $\phi=1$, the tax is neutral on consumption: $\frac{\partial c_{1 t}}{\partial \tau}=0$. This also can be explained by the intertemporal budget constraint with $\phi=1$ : $c_{1 t}+\frac{C_{2 t+1}}{1+r_{t+1}}=w_{t} e_{t}$.

${ }^{7}$ The intertemporal budget constraint is $c_{1 t}+\frac{c_{2 t+1}}{1+r_{t+1}}=w_{t} e_{t}+(1-\phi) \tau \frac{(1+n) w_{t+1} e_{t+1}-\left(1+r_{t+1}\right) w_{t} e_{t}}{1+r_{t+1}}$. 


\subsection{Technology and Perfect Foresight Equilibrium}

We assume that the production technology is the same as in the Ramsey model ${ }^{8}$ and CRS with Inada condition is satisfied. For simplicity, let us assume that there is no technological progress. Specifically let the functional form of the technology be

$$
Y_{t}=F\left(K_{t}, L_{t}\right)=K_{t}^{\alpha} L_{t}^{1-\alpha}
$$

Competitive market equilibrium induces each factor price to be paid out its marginal productivity.

$$
\begin{aligned}
r_{t} & =f^{\prime}\left(k_{t}\right)-\delta=\alpha k_{t}^{\alpha-1}-\delta \\
w_{t} & =f\left(k_{t}\right)-k_{t} f^{\prime}\left(k_{t}\right)=(1-\alpha) k_{t}^{\alpha}
\end{aligned}
$$

where $k_{t}=\frac{K_{t}}{L_{t}}$ and $f(k) \equiv F(k, 1)$. Capital accumulation should meet economy-wide saving level at equilibrium. In the model there are two channels of saving: private saving by households and public saving through payroll tax. The capital stock at $t+1$ is the amount saved by young individuals at period $t$ plus the amount invested at $t$ for social security income for period $t+1$. Because from all social security tax collection, only portion $\phi$ is saved and $(1-\phi)$ is allocated to the current old for their retirement benefit, the market clearing condition implies

$$
K_{t+1}=L_{t} S_{t+1}+\left(1+r_{t+1}\right) L_{t} \phi \tau_{t} w_{t} e_{t}
$$

where the saving for time $t+1$, i.e., $S_{t+1}$ is a function of $w_{t}$ and $r_{t+1}$ and the interest rate is assumed to be the same in both components of private and public saving. Dividing both sides by $L_{t}$ returns the following expression in capital per labor, $k_{t}=\frac{K_{t}}{L_{t}}$ :

$$
(1+n) k_{t+1}=S_{t+1}+\left(1+r_{t+1}\right) \phi \tau_{t} w_{t} e_{t}
$$

Substituting $r_{t+1}$ and $w_{t}$ into the above, together with letting $e_{t}=e_{t+1}=1$ generates the following law of motion:

$$
(1+n) k_{t+1}=\frac{\left[\beta\left(1+r_{t+1}\right)\right]^{1 / \gamma}\left(1-\tau_{t}\right) w_{t}-T_{t+1}}{\left(1+r_{t+1}\right)+\left[\beta\left(1+r_{t+1}\right)\right]^{1 / \gamma}}+\left(1+r_{t+1}\right) \phi \tau_{t} w_{t}
$$

where $T_{t+1}=\phi\left(1+r_{t+1}\right) \tau_{t} w_{t}+(1-\phi)(1+n) \tau_{t+1} w_{t+1}$. Replacing the variables defined above $\left(r_{t+1}, w_{t}\right.$ and $T_{t+1}$ equations) into the law of motion generates the following relationship among the variables ${ }^{9}$ : $(1+n) k_{t+1}=m\left(k_{t+1}, k_{t}, \tau_{t+1}, \tau_{t}: \phi\right)$. For the case of $u(c)=\log (c)^{10}$ and $\tau_{t}=\tau_{t+1}=\tau$, the equation returns to

$$
\frac{(1+n)}{(1-\alpha)} k_{t+1}=\frac{\beta(1-\tau)-\phi \tau}{(1+\beta)} k_{t}^{\alpha}-\frac{(1-\phi)(1+n) \tau k_{t+1}^{\alpha}}{(1+\beta)\left(1+\alpha k_{t+1}^{\alpha-1}-\delta\right)}+\left(1+\alpha k_{t+1}^{\alpha-1}-\delta\right) \phi \tau k_{t}^{\alpha}
$$

Before we study long run result through steady states from this equation, we want to revisit the question regarding the effect of $\phi$ and $\tau$ on the saving function and capital accumulation, but in equilibrium with all adjusted variables. From the market clearing condition (17), for $\tau_{t}=\tau_{t+1}=\tau$

$$
(1+n) k_{t+1}=S_{t+1}+\left(1+r_{t+1}\right) \phi \tau w_{t} \equiv Z_{t+1}
$$

where $Z_{t+1}$ is the total saving defined in previous section. Because $Z_{t+1}=f\left(r_{t+1}, w_{t}, w_{t+1}: \phi, \tau\right)=f\left(r\left(k_{t+1}\right), w\left(k_{t}\right), w\left(k_{t+1}\right): \phi, \tau\right)$ Equation (20) determines $k_{t+1}$ as an implicit function of $k_{t}, \phi$, and $\tau$. To get the effect of $\phi$ and $\tau$ on other variables, we need to derive all the partial derivatives from the equation. Thus, the total differentiation from Equation (20) gives

\footnotetext{
${ }^{8}$ The Ramsey model implies a representative firm in a decentralized economy with profit maximization of the following: $\pi_{i}=F\left(K_{i}, L_{i}\right)-(r+\delta) K_{i}-w L_{i}$.

${ }^{9}$ This is because $T_{t+1}=\phi\left(1+\alpha k_{t+1}^{\alpha-1}-\delta\right) \tau_{t}(1-\alpha) k_{t}^{\alpha}+(1-\phi)(1+n) \tau_{t+1}(1-\alpha) k_{t+1}^{\alpha}$.

${ }^{10}$ This implies $\gamma=1$ in CRRA.
} 


$$
\begin{aligned}
(1+n) \mathrm{d} k_{t+1}= & \frac{\partial Z_{t+1}}{\partial r} r^{\prime}\left(k_{t+1}\right) \mathrm{d} k_{t+1}+\frac{\partial Z_{t+1}}{\partial w} w^{\prime}\left(k_{t}\right) \mathrm{d} k_{t} \\
& +\frac{\partial Z_{t+1}}{\partial w} w^{\prime}\left(k_{t+1}\right) \mathrm{d} k_{t+1}+\frac{\partial Z_{t+1}}{\partial \phi} \mathrm{d} \phi+\frac{\partial Z_{t+1}}{\partial \tau} \mathrm{d} \tau
\end{aligned}
$$

Then each of the partial derivatives is represented by the notation of $\theta=\frac{1}{\left(1+r_{t+1}\right)+\left[\beta\left(1+r_{t+1}\right)\right]^{1 / \gamma}}$ as follows. Keep in mind that $0<\theta<1$.

$$
\begin{aligned}
& \frac{\partial Z_{t+1}}{\partial w_{t+1}}=-\theta(1-\phi)(1+n) \tau<0 \\
& \frac{\partial Z_{t+1}}{\partial w_{t}}=\theta(1-\tau)\left[\beta\left(1+r_{t+1}\right)\right]^{1 / \gamma}+(1-\theta)\left(1+r_{t+1}\right) \phi \tau>0
\end{aligned}
$$

Given a value of fundedness intensity $\phi$, the total saving increases when current income increases while it decreases with higher future income. But $\phi$ itself increases total saving as seen in Equation (9):

$\frac{\partial Z_{1 t+1}}{\partial \phi}=\theta(1+n) \tau w_{t+1}+(1-\theta)\left(1+r_{t+1}\right) \tau w_{t}>0$. Unlike these three, two other derivatives, $\frac{\partial Z_{t+1}}{\partial \tau}$ and $\frac{\partial Z_{t+1}}{\partial r}$ are not deterministic.

$$
\frac{\partial Z_{t+1}}{\partial \tau}=-\theta\left\{\left[\beta\left(1+r_{t+1}\right)\right]^{1 / \gamma} w_{t}+(1-\phi)(1+n) w_{t+1}\right\}+(1-\theta)\left(1+r_{t+1}\right) \phi w_{t}
$$

This shows that an increase in tax reduces private saving but increases public saving. The overall direction depends on the relative strength. Even more complicated effect comes from the interest rate change due to tradeoff between income and substitution effects, as well as lifecycle wealth change. That is, $\frac{\partial Z_{t+1}}{\partial r} \lessgtr 0^{11}$. When the interest rate increases, given fundedness intensity, it increases publicly saved amounts through $T_{t+1}$. However, increased $T_{t+1}$ tends to decrease the incentive for private saving, while the private saving itself is subject to income and substitution effects in an inter-temporal choice when there is an increase in the price, i.e., $-\frac{1}{1+r_{t+1}}$. Together with these, it is also true that $r_{t}^{\prime}\left(k_{t}\right)=-\alpha(1-\alpha) k_{t}^{\alpha-2}<0$ and $w_{t}^{\prime}\left(k_{t}\right)=\alpha(1-\alpha) k_{t}^{\alpha-1}>0$. Collecting all the components, the overall effects of $\phi$ and $\tau$ on $k_{t+1}$ in adjusted variables are

$$
\begin{gathered}
\frac{\partial k_{t+1}}{\partial \phi}=\frac{\frac{\partial Z_{t+1}}{\partial \phi}}{(1+n)-\frac{\partial Z_{t+1}}{\partial r} r^{\prime}\left(k_{t+1}\right)-\frac{\partial Z_{t+1}}{\partial w} w^{\prime}\left(k_{t+1}\right)} \\
\frac{\partial k_{t+1}}{\partial \tau}=\frac{\frac{\partial Z_{t+1}}{\partial \tau}}{(1+n)-\frac{\partial Z_{t+1}}{\partial r} r^{\prime}\left(k_{t+1}\right)-\frac{\partial Z_{t+1}}{\partial w} w^{\prime}\left(k_{t+1}\right)}
\end{gathered}
$$

$$
\begin{aligned}
& \frac{\partial Z_{t+1}}{\partial r}=-\frac{\left(\left[\beta\left(1+r_{t+1}\right)\right]^{\frac{1}{\gamma}}(1-\tau) w_{t}-\phi\left(1+r_{t+1}\right) \tau w_{t}-(1-\phi)(1+n) \tau w_{t+1}\right)\left(1+\frac{\beta}{\gamma\left[\beta\left(1+r_{t+1}\right)\right]^{\frac{1}{\gamma}}}\right)}{\left(1+r_{t+1}+\left[\beta\left(1+r_{t+1}\right)\right]^{\frac{1}{\gamma}}\right)^{2}} \\
& +\theta\left(\frac{\beta}{\gamma\left[\beta\left(1+r_{t+1}\right)\right]^{1 / \gamma-1}(1-\tau) w_{t}}-\phi \tau w_{t}\right)+\phi \tau w_{t} .
\end{aligned}
$$




$$
\frac{\partial k_{t+1}}{\partial k_{t}}=\frac{\frac{\partial Z_{t+1}}{\partial w} w^{\prime}\left(k_{t}\right)}{(1+n)-\frac{\partial Z_{t+1}}{\partial r} r^{\prime}\left(k_{t+1}\right)-\frac{\partial Z_{t+1}}{\partial w} w^{\prime}\left(k_{t+1}\right)}
$$

Because it is satisfied that $\frac{\partial Z_{t+1}}{\partial w}<0$ and $w^{\prime}\left(k_{t+1}\right)>0$ if $\frac{\partial Z_{t+1}}{\partial r}$ is positive then all the denominators are positive. Even though it is negative, if it is not too big in absolute value so that it is satisfied $(1+n)-\frac{\partial Z_{t+1}}{\partial w} w^{\prime}\left(k_{t+1}\right)>\frac{\partial Z_{t+1}}{\partial r} r^{\prime}\left(k_{t+1}\right)$ then we have positive denominators for all the cases and thus direction of changes solely depends on the numerators. If this is the case here, then it is straight forward to have $\frac{\partial k_{t+1}}{\partial \phi}>0$ and $\frac{\partial k_{t+1}}{\partial k_{t}}>0$. For the case of $\frac{\partial k_{t+1}}{\partial \tau}$ because $\frac{\partial Z_{t+1}}{\partial \tau}$ is not deterministic, the overall result is ambiguous.

\section{Long-Run Equilibrium}

In this section, we explore the long-run effect of transition toward more funded system by analyzing the change of variables at steady states. We start with the law of motion in Equation (19) steady states and analyze the effect of parameter change on the main variables studied above. Because of the implicit relation among variables, the Equation (19) does not generate closed form solutions for steady states. However, given a specific value of $\phi$, it is possible to obtain those solutions. In the Appendix, two closed form solutions are obtained with the main social security system: PAYG and Fully-Funded. Once the steady state capital level $k^{*}$ is obtained, all other steady state variables, such as steady state saving and consumption are determined. They are

$$
\begin{aligned}
& S_{1}=\frac{w^{*}}{1+\beta}\left(\beta(1-\tau)-\phi \tau-(1-\phi) \tau \frac{1+n}{1+r^{*}}\right) \\
& Z_{1}=\frac{w^{*}}{1+\beta}\left(\beta(1-\tau)-\phi \tau-(1-\phi) \tau \frac{1+n}{1+r^{*}}\right)+\phi\left(1+r^{*}\right) \tau w^{*} \\
& c_{1}=\frac{w^{*}}{1+\beta}\left((1-\tau)+\phi \tau+(1-\phi) \tau \frac{1+n}{1+r^{*}}\right) \\
& c_{2}=\frac{w^{*} \beta\left(1+r^{*}\right)}{1+\beta}\left((1-\tau)+\phi \tau+(1-\phi) \tau \frac{1+n}{1+r^{*}}\right)
\end{aligned}
$$

where $r^{*}=r\left(k^{*}\right)=\alpha k^{*(\alpha-1)}-\delta$ and $w^{*}=w\left(k^{*}\right)=(1-\alpha) k^{* \alpha}$. Next is to analyze the long-run effect of the fundedness on saving rates, consumption, and capital accumulation. From the steady state saving equation (28), the partial derivative w.r.t. $\phi$ is

$$
\frac{\partial S_{1}}{\partial \phi}=\frac{w^{*}}{1+\beta}\left(\frac{n-r^{*}}{1+r^{*}}\right) \tau
$$

It is straight forward that given steady state wage rate and interest rate, higher fundedness intensity increases private saving if the population growth rate is greater than the steady state net return to capital. Likewise if population growth rate is lower than the net return, then the saving decreases: $\frac{\partial S_{1}}{\partial \phi}<0$. Regarding the effect on consumption, the opposite result is obtained because

$$
\frac{\partial c_{1}}{\partial \phi}=\frac{w^{*}}{1+\beta}\left(\frac{r^{*}-n}{1+r^{*}}\right) \tau
$$

To see the effect of $\phi$ on capital accumulation, we need to get partial derivative of $k: \frac{\partial k}{\partial \phi}$. Because the law of 
motion is an implicit function of capital and fundedness intensity, we need to obtain this through implicit differentiation: from Equation (19), the partial derivative w.r.t. $\phi$ around the steady state capital is

$$
\frac{\partial k}{\partial \phi}=\tau \frac{\left(1+\alpha k^{\alpha-1}-\delta\right)^{2}(1+\beta)+(1+n)-\left(1+\alpha k^{\alpha-1}-\delta\right)}{\left(\left(1+\alpha k^{\alpha-1}-\delta\right)(1+\beta)\right.}>0
$$

for positive net rate because $\left(1+\alpha k^{\alpha-1}-\delta\right)^{2}(1+\beta)+(1+n)>1+\alpha k^{\alpha-1}-\delta$, together with $1-\alpha>0$ and $1-\phi>0$. This finding implies that transition from less funded system to more funded one would increase capital accumulation in the long run. Let us turn to the effect from tax rate change. What would happen to saving, consumption and capital accumulation if the tax rate increases given any fundedness intensity? Again from the saving function (28), the long-run effect of tax rate change is

$$
\frac{\partial S_{1}}{\partial \tau}=-\frac{w^{*}}{1+\beta}\left(\beta+\phi+(1-\phi) \frac{1+n}{1+r^{*}}\right)<0
$$

Regardless of intensity level, a higher payroll tax induces lower private saving in the long run. For the direction of consumption from tax rate is

$$
\frac{\partial c_{1}}{\partial \tau}=\frac{w^{*}}{1+\beta}\left((1-\phi) \frac{n-r^{*}}{1+r^{*}}\right)
$$

which is positive if $n>r^{*}$ but negative if $n<r^{*}$ for all values of $0 \leq \phi<1$. But at $\phi=1$ the fully funded system, it is true that $\frac{\partial c_{1}}{\partial \tau}=0$, implying consumption level does not depend on tax level, i.e., tax is not distorting. Overall, the effect on consumption is not conclusive. Finally, for the effect of capital accumulation, we again use implicit differentiation to get

$$
\frac{\partial k}{\partial \tau}=\frac{\left(1+\alpha k^{\alpha-1}-\delta\right) \phi-\frac{(\beta+\phi)}{(1+\beta)}-\frac{(1-\phi)(1+n)}{(1+\beta)\left(1+\alpha k^{\alpha-1}-\delta\right)}}{\left(\left(\frac{1+n}{1-\alpha}\right) k^{-\alpha}-\frac{(1-\phi)(1+n) \tau \alpha k^{\alpha-2}}{(1+\beta)\left(1+\alpha k^{\alpha-1}-\delta\right)^{2}}+\phi \tau \alpha k^{\alpha-2}\right)(1-\alpha)}
$$

The result is ambiguous. However, for the case of $\phi=0$, a higher tax rate increases capital level for $0<k<\left(\frac{\sqrt{\frac{(1-\alpha) \tau \alpha}{(1+\beta)}}-\alpha}{1-\delta}\right)^{\frac{1}{1-\alpha}}$ at steady states. Likewise for the case of $\phi=1$, higher tax implies higher capital level when $0<k<\left(\frac{\alpha}{\delta}\right)^{\frac{1}{1-\alpha}}$.

\section{Comparison}

In this subsection, we specifically compare the three social security systems, PAYG, Partially Funded and Fully Funded, in terms of the three main variables at steady states. For this comparison, it is necessary to set the initial steady states of each system at the same level: $k_{\mathrm{PAYG}}^{*}=k_{\mathrm{PF}}^{*}=k_{\mathrm{FF}}^{*}$. First regarding the saving, the three types of saving functions are 


$$
\begin{aligned}
& S_{1}^{\mathrm{PAYG}}=\frac{w^{*}}{1+\beta}\left(\beta(1-\tau)-\tau \frac{1+n}{1+r^{*}}\right) \\
& S_{1}^{\mathrm{PF}}=\frac{w^{*}}{1+\beta}\left(\beta(1-\tau)-\phi \tau-(1-\phi) \tau \frac{1+n}{1+r^{*}}\right) \\
& S_{1}^{\mathrm{FF}}=\frac{w^{*}}{1+\beta}(\beta(1-\tau)-\tau)
\end{aligned}
$$

Because the first terms in each of the equations are identical, we can focus only on the second terms: because $(1+\beta)>0$ and $(1+n)>0$, for all $0<\phi<1$ it is true that if $1+r^{*}<1+n$

$$
-\tau \frac{1+n}{1+r^{*}}<-\phi \tau-(1-\phi) \tau \frac{1+n}{1+r^{*}}<-\tau
$$

implying $S_{1}^{\mathrm{PAYG}}<S_{1}^{\mathrm{PF}}<S_{1}^{\mathrm{FF}}$. Likewise, if the opposite is assumed, $1+r^{*}>1+n$ then $S_{1}^{\mathrm{PAYG}}>S_{1}^{\mathrm{PF}}>S_{1}^{\mathrm{FF}}$. If the steady state population growth rate is greater than the steady state interest rate, then the households under Fully-Funded system save more. For a matured or stalled economy such as the case where there is little population growth so that $1+r^{*}>1+n$ it is easy to see that the households under PAYG system save more. And for a special case of $1+n=1+r^{*}$ all of the three systems give the same saving rate for all $0<\phi<1$. In a dynamic system, however, this condition may be interpreted in terms of capital stock. That is, what would be the steady state capital stock under which all the three social security systems generate the same saving rate regardless of intensity of fundedness. To see this we need to get capital level which makes the three saving functions are equal to each other or simply the capital level that makes $n=r^{*}$ from above argument. Because $r^{*}=\alpha k^{\alpha-1}-\delta$ the identity condition yields $1+n=1+\alpha k^{*(\alpha-1)}-\delta$. Therefore, the steady state capital that generates the same saving rate is

$$
k^{*}=\left(\frac{\alpha}{n+\delta}\right)^{\alpha-1}
$$

Next is the capital accumulation. Because of the interdependence of many variables, it may not be possible to get the direct comparison of steady state capital level among the different systems. Instead we want to demonstrate this numerically. Thus for the parameters of $\{\alpha, \beta, \delta, \tau, n\}=\{0.33,0.9,0.1,0.1,0.1\}$, the steady state capital level is obtained in Figure 1.

The capital level in graph appeals to the intuitive notion that fully funded social security would give an economy a higher incentive to accumulate capital. Finally, we want to compare the welfare of the households in each system. Because we assume log utility and this function is monotonic in consumption, the first period consumption determines the relative value of the utility. From Equation (30), we obtain the relationship among the steady state consumption profiles of the three social security plans. It may be convenient to describe both the PAYG consumption and Partially Funded consumption in term of the one in the Fully Funded system. Thus we have

$$
\begin{aligned}
& c_{1}^{\mathrm{PAYG}}=c_{1}^{\mathrm{FF}}+\frac{\tau w^{*}\left(n-r^{*}\right)}{(1+\beta)\left(1+r^{*}\right)} \\
& c_{1}^{\mathrm{PF}}=c_{1}^{\mathrm{FF}}+\frac{(1-\phi) \tau w^{*}\left(n-r^{*}\right)}{(1+\beta)\left(1+r^{*}\right)}
\end{aligned}
$$

Therefore, at steady states, if $n>r^{*}$, then for all $0<\phi<1$ it is true that $c_{1}^{\mathrm{PAYG}}>c_{1}^{\mathrm{PF}}>c_{1}^{\mathrm{FF}}$. Also, if $n<r^{*}$, then $c_{1}^{\mathrm{PAYG}}<c_{1}^{\mathrm{PF}}<c_{1}^{\mathrm{FF}}$ for all $0<\phi<1$. In fact, the same ranking applies to the second period consumption because

$$
\begin{aligned}
& c_{2}^{\mathrm{PAYG}}=c_{2}^{\mathrm{FF}}+\frac{\beta}{(1+\beta)} \tau w^{*}\left(n-r^{*}\right) \\
& c_{2}^{\mathrm{PF}}=c_{2}^{\mathrm{FF}}+\frac{\beta(1-\phi) \tau w^{*}\left(n-r^{*}\right)}{(1+\beta)}
\end{aligned}
$$




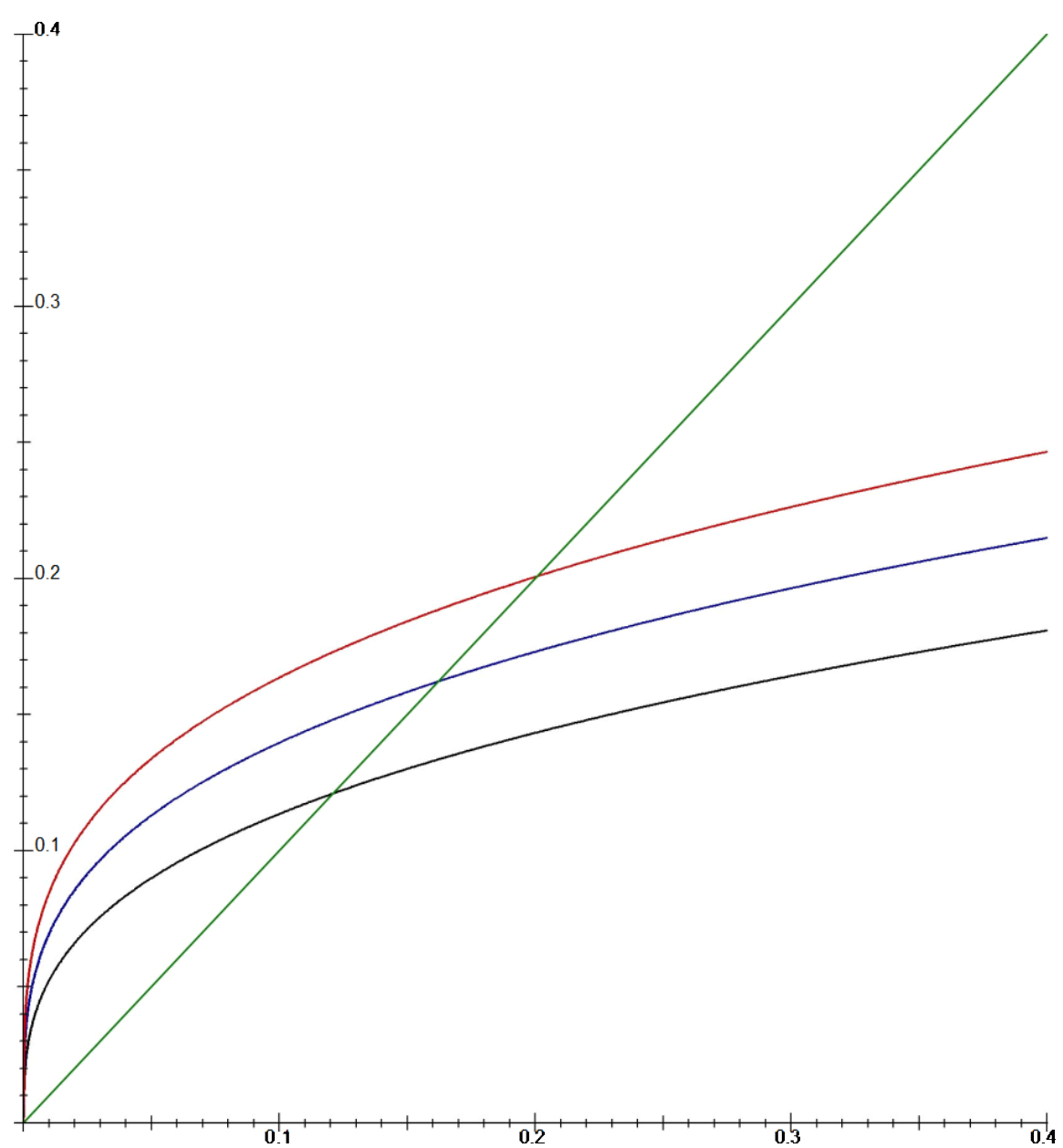

Figure 1. Steady state capital: the red curve is from $\phi=1$, the blue one from $\phi=1 / 2$, and the black one from $\phi=0$. The green line is at $k_{t+1}=k_{t}$.

This implies that if the long term population growth rate is higher than the steady state net return to capital, then because the PAYG consumption in both periods is greater than the one in Fully Funded, PAYG utility is greater than the Fully Funded utility ${ }^{12}$, i.e., $U^{\mathrm{PAYG}}\left(c_{1}, c_{2}\right)>U^{\mathrm{PF}}\left(c_{1}, c_{2}\right)>U^{\mathrm{FF}}\left(c_{1}, c_{2}\right)$. However for the economy with low population growth rate, the overall result is ambiguous.

\section{Conclusion}

This paper develops a model of a unified social security system by which different social security plans are represented via certain degrees of fundedness and analyzes the inter-generational distribution of consumption and saving in general equilibrium. This paper specifically examines the effect of transition toward more funded system on capital accumulation. The result shows that as we move toward more funded system, the capital accumulation tends to increase as the total saving from both private and public savings increases. Only if the income effect from interest rate change is so strong to make the total saving decreases severely, then the more funded system may not produce this outcome. Also increase in the intensity of fundedness increases saving but decreases consumption, when population growth rate is greater than the net return to capital. This paper derives closed form solutions and demonstrates the direct effect of parameter change on many variables under different social security plans: given a partially funded plan, an increase in tax rate increases public saving but decreases private saving unambiguously, while the effect on consumption and capital accumulation are not conclusive.

${ }^{12} c_{1}^{\mathrm{PAYG}}>c_{1}^{\mathrm{FF}}$ and $c_{2}^{\mathrm{PAYG}}>c_{2}^{\mathrm{FF}}$, thus $U^{\mathrm{PAYG}}\left(c_{1}, c_{2}\right)>U^{\mathrm{FF}}\left(c_{1}, c_{2}\right)$. 


\section{References}

[1] Feldstein, M. (2005) Structural Reform of Social Security. Journal of Economic Perspectives, 19, 33-55. http://dx.doi.org/10.1257/0895330054048731

[2] Kunze, L. (2012) Funded Social Security and Economic Growth. Economics Letters, 115, 180-183. http://dx.doi.org/10.1016/j.econlet.2011.11.032

[3] Kaganovich, M. and Zilcha, I. (2012) Pay-As-You-Go or Funded Social Security? A General Equilibrium Comparison. Journal of Economic Dynamics \& Control, 36, 455-467. http://dx.doi.org/10.1016/j.jedc.2011.03.015

[4] Attanasio, O., Kitao, S. and Violante, G. (2007) Global Demographic Trends and Social Security Reform. Journal of Monetary Economics, 54, 144-198. http://dx.doi.org/10.1016/j.jmoneco.2006.12.010

[5] Aubuchon, C.P., Conesa, J.C. and Garriga, C. (2011) A Primer on Social Security Systems and Reforms. Federal Reserve Bank of St. Louis Review, 93, 19-35.

[6] Geanakoplos, J. and Zeldes, S. (2008) Reforming Social Security with Progressive Personal Accounts. NBER Working Paper No. 13979.

[7] Gonzalez-Eiras, M. and Niepelt, D. (2008) The Future of Social Security. Journal of Monetary Economics, 55, 197218. http://dx.doi.org/10.1016/j.jmoneco.2007.10.005

[8] De La Croix, D. and Michel, P. (2002) A Theory of Economic Growth: Dynamics and Policy in Overlapping Generations. Cambridge University Press, Cambridge. http://dx.doi.org/10.1017/CBO9780511606434

[9] Diamond, P. and Orszag, P.R. (2005) Saving Social Security. Journal of Economic Perspectives, 19, 11-32. http://dx.doi.org/10.1257/0895330054048722

[10] Jimeno, J.F., Rojas, J.A. and Puente, S. (2008) Modelling the Impact of Aging on Social Security Expenditures. Economic Modelling, 25, 201-224. http://dx.doi.org/10.1016/j.econmod.2007.04.015

[11] Hines, J.R. and Taylor, T. (2005) Short Falls in the Long Run: Predictions about the Social Security Trust Fund. Journal of Economic Perspectives, 19, 3-9. http://dx.doi.org/10.1257/0895330054048759

[12] Pecchenino, R.A. and Utendorf, K.R. (1999) Social Security, Social Welfare and the Aging Population. Journal of Population Economics, 12, 607-623. http://dx.doi.org/10.1007/s001480050116

[13] Lambrecht, S., Michel, P. and Vidal, J.-P. (2005) Public Pensions and Growth. European Economic Review, 49, 12611281. http://dx.doi.org/10.1016/j.euroecorev.2003.09.009 


\section{Appendix}

\section{Steady States in Closed Form}

The closed form solutions of steady states are obtained from the law of motion (19), setting $k_{t}=k_{t+1}=k$. Let the payroll tax rate be constant, $\tau_{t}=\tau$ for all $t$. Then under the PAYG social security system in which $\phi=0$, the steady state condition implies

$$
\frac{1+n}{1-\alpha}=k^{\alpha-1} \frac{\beta(1-\tau)\left(1+\alpha k^{\alpha-1}-\delta\right)-(1+n) \tau}{(1+\beta)\left(1+\alpha k^{\alpha-1}-\delta\right)} .
$$

By rearranging, the closed form solution is obtained by $A k^{2(\alpha-1)}+B k^{\alpha-1}+C=0$, with coefficients:

$$
\left\{\begin{array}{l}
A=\alpha \beta(1-\alpha)(1-\tau) \\
B=(1-\alpha)[\beta(1-\tau)(1-\delta)-\tau(1+n)]-\alpha(1+n)(1+\beta) \\
C=-(1-\delta)(1+n)(1+\beta)
\end{array}\right.
$$

The steady state is obtained at the capital level of

$$
k_{\mathrm{PAYG}}^{*}=\left(\frac{-B \pm \sqrt{B^{2}-4 A C}}{2 A}\right)^{-\frac{1}{1-\alpha}}
$$

Under the Fully-Funded social security system where $\phi=1$, the law of motion returns to

$$
\frac{1+n}{1-\alpha}=k^{\alpha-1}\left(\frac{\beta}{1+\beta}+\left(\alpha k^{\alpha-1}-\delta\right) \tau\right)
$$

Rearranging to get

$$
\tau \alpha(1+\beta) k^{2(\alpha-1)}+[\beta-\delta \tau(1+\beta)] k^{\alpha-1}-(1+\beta)(1+n)(1-\alpha)^{-1}=0
$$

Thus we get the following closed form solution:

$$
k_{\mathrm{FF}}^{*}=\left(\frac{(\tau(1+\beta) \delta-\beta) \pm \sqrt{(\tau(1+\beta) \delta-\beta)^{2}+4 \tau(1+\beta) \alpha\left((1+n)(1+\beta)(1-\alpha)^{-1}\right)}}{2 \tau(1+\beta) \alpha}\right)^{-\frac{1}{1-\alpha}}
$$


Scientific Research Publishing (SCIRP) is one of the largest Open Access journal publishers. It is currently publishing more than 200 open access, online, peer-reviewed journals covering a wide range of academic disciplines. SCIRP serves the worldwide academic communities and contributes to the progress and application of science with its publication.

Other selected journals from SCIRP are listed as below. Submit your manuscript to us via either submit@scirp.org or Online Submission Portal.
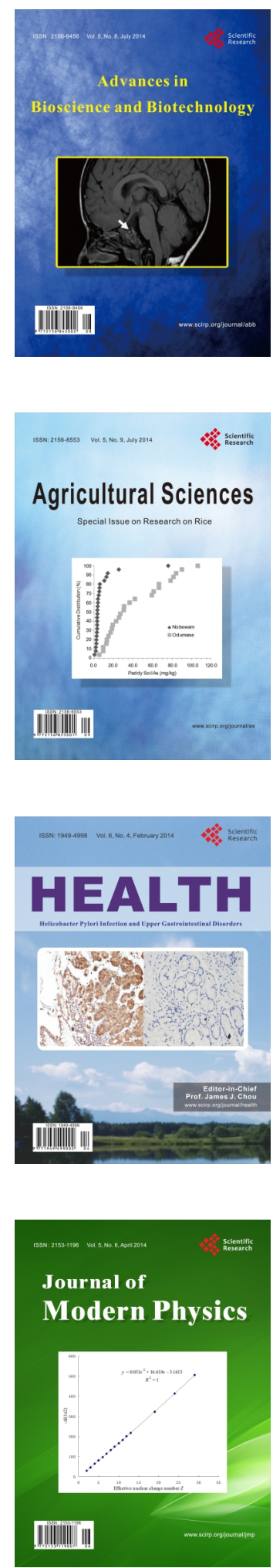
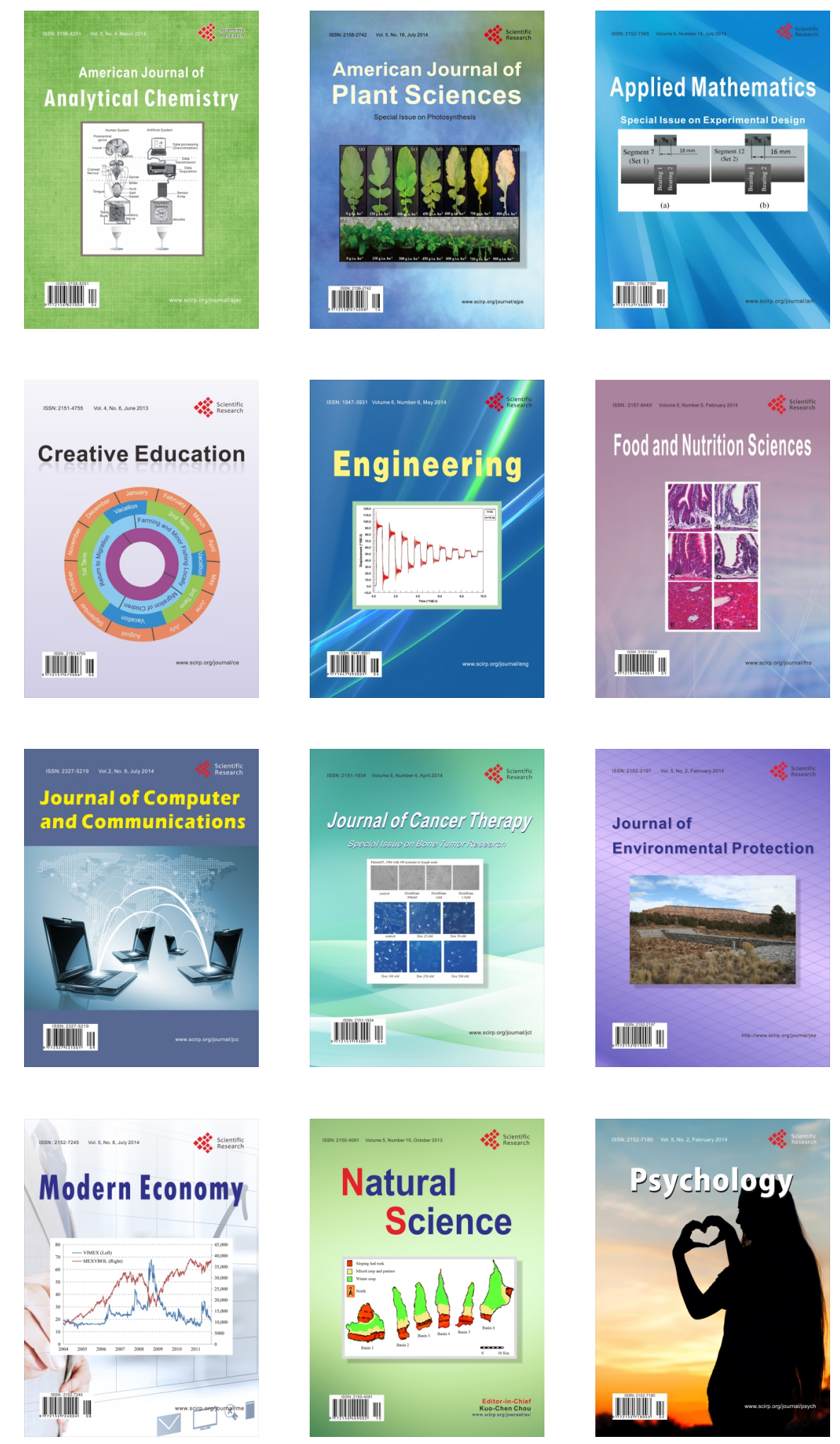